\title{
Processing Instruction and the Learning of English Adjectives by Brazilian Students
}

\author{
Daniel Ortins Salerno \\ Universidade de São Paulo
}

\begin{abstract}
This study aimed at assessing the effectiveness of the foreign language pedagogical intervention Processing Instruction (PI) in helping Brazilian learners in acquiring adjective phrases in English. Following the pre-tests, administered to 51 students, groups were randomly assigned to one of two pedagogical interventions: PI and traditional and to one of two programs, extensive and intensive. Learners received photos next to sentences in Portuguese to which they wrote a translation in English. Wrong or blank responses were scored zero, correct answers scored one. The MannWhitney test revealed no significant differences among the groups before the interventions. However, the results indicated significant differences between the pre and post-test (34.65) ( $p<0,001)$ for PI. Although both interventions seemed to have affected the learning of the adjective phrases studied, it appears that PI had a more significant effect on learning than the traditional instruction in extensive and intensive programs.
\end{abstract}

\section{Introduction}

Second Language Acquisition (SLA) is a vast and complex area that links Linguistics to Psycholinguistics. As the cognitive approach account of the language acquisition in Psychology was taking shape, a large array of phenomena pertaining the learning of a foreign language started to attract the interest of an ever increasing number of researchers. Ellis divided the SLA research into two large areas: the general study of SLA and the study of the role of instruction in it [1].

It is generally known that a great part of language learning may be achieved by means of a communicative approach without any formal instruction. However, Ellis observes that there are indeed certain linguistic properties that may never be learnt or acquired unless they are instructed [1]. This approach of instructed SLA is called form-focused instruction.

Recent studies suggest that form-focused instruction can lead to positive effects on the development of the learners' grammar [1] [6] [8]. In this approach of SLA, a considerable number of researchers have set out to understand whether the input, when enhanced, might eliminate persistent grammar errors. There are indeed a number of reasons to justify why the input, rather the output has been attracting so much attention in SLA.

Linguistic input is the raw material for L2 acquisition. It is defined as "language that encodes meaning" [7]. However, it is not simply a set of formal linguistic explanations on how a given language functions in the sentence level or in the lexical domain. A number of cognitive mechanisms such as attention, working memory and restructuring, just to name a few, use input throughout the process of L2 acquisition. Linguistic input involves grammar form and meaning. In other words, an utterance is part of a representational and referential system of meaning and form. In the SLA context, it means that L2 learners need to resort to cognitive resources that are capable of processing the information so that there may be comprehension. From their comprehension, learners are able to form mental representations of the grammar of a given language.

The importance of input was also stressed by as he proposed his model of L2 acquisition [10]. According to him, comprehension is essential and the need to extract meaning surpasses any concern that may appear to focus on form. As they focus on meaning, learners would unconsciously make any changes needed in their representational system of the L2 grammar [2]. Nevertheless, it has to be stressed that there is indeed an important distinction between input comprehension and input processing. While the former not always leads to L2 acquisition, the latter generally succeeds, as it comprises strategies and mechanisms involved in form-meaning connections. These are the connections needed to convert input into intake, in other words, in accessible content to long-term memory.

The approach studied in this paper, proposed by VanPatten, is called Processing Instruction, (PI). He observes that an important role for instruction in SLA is altering the way the input is noticed and processed by learners [7]. The figure below illustrates how the set of processes involved in SLA occur.

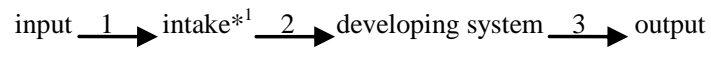

Figure 1. Cognitive processes involved in L2 acquisition.

\footnotetext{
1 Intake is defined by Ellis as "that portion of input that learners notice and therefore take into temporary memory. Intake may subsequently accommodated in the leaner's interlanguage system (i.e. become part of long-term memory). However, not all intake is so accommodated [1].
} 
VanPatten considers that the learners' attentional system becomes overwhelmed as it tackles foreign language input [5]. Consequently, leaners must pay attention to form and meaning simultaneously as they read or listen to utterances in real time. The PI model also assumes that mechanisms of implicit learning interact with the input processing. This pedagogical intervention has the following characteristics [6]:

- it is predicated on what learners do (and do not do) during input processing (i.e., sentence-level processing strategies for connecting form and meaning);

- $\quad$ it is input oriented (learners are not required to produce the targeted item during the treatment);

- input is manipulated in particular ways to alter processing strategies and increase better intake for acquisition (structured input);

- it includes explicit information for the learner on both grammatical structure and processing problems;

- it follows certain guidelines for the creation of structured input activities.

The figure 2, below illustrates how the intervention functions:

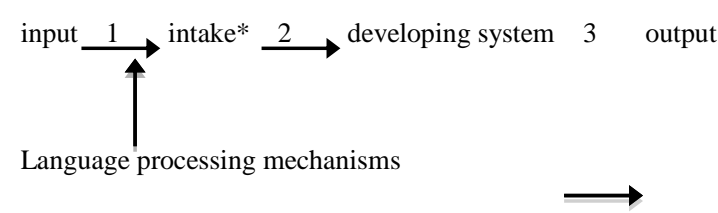

Focused practice

\section{Figure 2. Processing Instruction (PI) in second language learning.}

The Processing Instruction pedagogical intervention assumes a very important role for the working memory. VanPatten observes that it has a limited capacity to process information in real time and, therefore, it has to make room, so to speak, to new incoming information. In other words, the working memory must discard irrelevant data in order to be able to process ongoing facts into learners' cognitive system. One of the principles proposed by VanPatten to explain how the input in L2 interacts with the working memory is that learners process content words before anything else [5].

The hypothesis of this research, was that Brazilian learners of English when facing adjective phrases such as "I am thirsty", would only process the words with referential meaning (content words) and would ignore the others. As learners read or listen to the sentence, they would ignore the verb to be and would process the lexical item after it (in this example, the adjective "thirsty"). Consequently, they would assume that this adjective has the same grammatical class as it has in Brazilian Portuguese, i.e., a noun. In Brazilian Portuguese, these sentences are processed by making use of nouns, preceded by a preposition ("Eu estou com medo", literally, "I am with fear"). Considering that, the same kind of processing is expected to be more frequently observed in the group receiving traditional instruction, TI, while in the Processing Instruction group, PI, the frequency of this type of error would be significantly lower due to this type of instruction. Brazilian learners of English very often produce the following sentences (note that these sentences are considered agrammatical in English):

*I have sure. (In Portuguese: 'Eu tenho certeza')

*I have afraid. (In Portuguese: 'Eu tenho medo')

*I am with sleep. (In Portuguese: Eu estou com sono)

Therefore, we assume that two processes take place in these type of errors, namely: transfer from the native language, Portuguese and the Lexical Preference principle, as explained in the previous paragraph.

On the other hand, the traditional instruction, TI, does not address potential problems of processing in L2 acquisition seeing that any comparisons with L1 are discouraged or simply banned. Furthermore, TI, is focused on practicing the target form that has been taught. Initially it takes shape in the form of explicit explanation followed by modeled dialogues that may involve drills. The last part of the instruction usually uses less controlled activities to practice the target form.

The research also aimed at testing the type of course, extensive or intensive as to whether this variable would influence the acquisition of these adjective phrases. Our research questions were the following:

Will learners who receive the pedagogical intervention PI show significantly higher gains in the posttest when compared to learners who received traditional instruction?

Will there learners in intensive courses have higher gains than those in regular programs?

\section{Method}

\subsection{Participants}

A total of 51 students and 6 teachers participated in this experiment. Learners were graduate and undergraduate students from six sections of the second level of the elementary course at a private 
English School. All participants, including the teachers were native speakers of Portuguese and had received formal instruction of the target structure in the previous level of the course. They were randomly distributed in two programs: extensive and intensive courses and into two groups of instructions: PI (experimental), Processing Instruction and TI (Traditional Instruction).

\subsection{Materials}

A 20 -item pre-test was administered. Six items used the target form while 14 were distractors.

The six experimental questions had one picture, next to a sentence in Portuguese, to which the subjects were supposed to write the correct description in English.

\subsection{Post-test:}

The posttest had 11 questions from which six were the same as the ones in the pre-test.

All questions had one picture, next to a sentence in Portuguese, to which learners were supposed to write a matching sentence in English.

\subsection{Procedures}

All the phases of the experiment were conducted in participants' regular classrooms and days of the week. The groups of intensive classes, 21 students, had classes everyday. They were randomly assigned to either the PI or the TI classes. The first day, on Tuesday, students completed an informed consent. They had two consecutive days of treatment of one hour each. On Friday, they had a posttest after their regular class. On the other hand, students taking regular courses, two times a week, in both PI and TI groups had two classes per week of $1 \mathrm{~h} 40$. However, they had one treatment per week, as we were informed that absenteeism is rather high towards the end of the week. All six teachers were carefully trained by the researcher and followed the guidelines for the interventions in both types of instruction, TI and PI.

Learners' usual teachers instructed both groups, TI and PI, and the researcher stayed in the class observing the treatment with no participation in the teaching process.

On the first day of the treatment, learners had a warm-up activity, which was exactly the same for both PI and TI groups. The PI group had an explanation of how adjectives are used in English (Appendix D). Furthermore, they were informed that the processing of some adjectives, indicating psychological states, do not follow the same processing as in Portuguese. This explanation was in Portuguese whereas in TI groups, the explanation was in English. After that explicit instruction, they received activities called structured input (SI). Those are designed to make form-meaning connections. Students got a brochure with two alternatives as possible replies to the sentences their teachers were supposed read to them. They had to choose the best picture to match the sentences and got the feedback immediately after their replies, without further clarifications. Teachers just replied 'correct' or 'incorrect'. The following item illustrates how the structured input activities work (Appendix A and B):

The teacher reads aloud to the class: "This is woman is afraid".

Students read in their brochures and choose the best alternative:

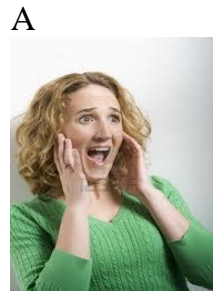

B is afraid.

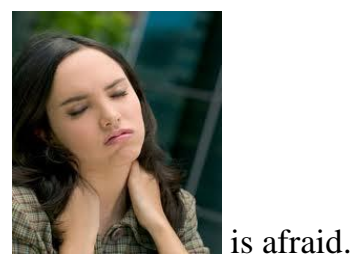

After this set of activities, students had a second day of treatment when they had to follow more SI activities. This time, oral affective activities were used give the students more opportunities to make form-meaning connections on communicative contexts. They were engaged in meaningful pair work with a set of questions to which they had to express their opinions. They expressed themselves without feedback from the teacher (Appendix C).

The post-tests were conducted one week after the second day of treatment for the extensive course and one day after the second day for the intensive course. Responses were scored zero, if subjects wrote either a wrong sentence or left a question blank, and one, if they wrote a correct answer.

\section{Results}

The raw mean scores in pre-tests in extensive program were 2.35 in traditional and 2.06 in processing whereas in intensive programs, 2.61 in TI and 1.87 in PI. The raw mean scores in post-test in extensive program were 3.57 in $\mathrm{TI}$ and 5.31 in PI, whereas in intensive programs, 4.46 in TI and 5.87 in PI.

The Mann-Whitney test revealed no significant differences among the groups before the interventions. However, the results indicated significant differences between the pre and post-test (34.65) $(\mathrm{p}<0,001)$ for PI. This could mean that any gains in the posttest are probably due to the type of instruction adopted. 
TABLE 1. Results of the Mann-Whitney test for the pre and posttests.

\begin{tabular}{|l|l|l|l|}
\hline Comparisons & Statistics & Pretests & Posttests \\
\hline \multirow{5}{*}{ TI vs PI } & Mann-Whitney U & 255.500 & 116.500 \\
\cline { 2 - 4 } & Wilcoxon W & 555.500 & 494.500 \\
\cline { 2 - 4 } & $\mathrm{Z}$ & -1.329 & -4.098 \\
\cline { 2 - 4 } & $\begin{array}{l}\text { Asymptotic } \\
\text { significance (2-tailed) }\end{array}$ & 0.184 & 0.000 \\
\hline
\end{tabular}

Learners of both instructions showed same prior knowledge. Although both interventions seemed to have affected the learning of the adjective phrases studied, it appears that PI had a more significant effect on learning than the traditional instruction in both extensive and intensive program.

The chart below shows the results of the MannWhitney test in pre and post-test of both types of instructions, TI and PI, and kinds of courses, extensive and intensive. The intensive program showed gains significantly higher when compared to TI intensive $(\mathrm{p}<0,001)$.

TABLE 2. Results of the Mann-Whitney test for the pre and posttests comparing the variable type of course.

\begin{tabular}{|c|c|c|c|}
\hline Comparisons & Statistics & Pretest & Posttest \\
\hline \multirow{5}{*}{$\begin{array}{l}\text { TI regular } \\
\text { vs } \\
\text { PI regular }\end{array}$} & Mann-Whitney U & 99.000 & 47.500 \\
\hline & Wilcoxon W & 235.000 & 152.500 \\
\hline & Z & -0.556 & -2.797 \\
\hline & $\begin{array}{l}\text { Asymptotic } \\
\text { significance (2-tailed) }\end{array}$ & 0.578 & 0.005 \\
\hline & $\begin{array}{l}\text { Exact significance } \\
{[2 * \text { (uni-tailed)] }}\end{array}$ & 0.608 & 0.006 \\
\hline \multirow{5}{*}{$\begin{array}{l}\text { TI intensive } \\
\text { vs } \\
\text { PI intensive }\end{array}$} & Mann-Whitney U & 34.000 & 7.000 \\
\hline & Wilcoxon W & 70.000 & 98.000 \\
\hline & Z & -1.364 & -3.435 \\
\hline & $\begin{array}{l}\text { Asymptotic } \\
\text { significance (2-tailed) }\end{array}$ & 0.173 & 0.001 \\
\hline & $\begin{array}{l}\text { Exact significance } \\
{[2 * \text { (uni-tailed)] }}\end{array}$ & 0.210 & 0.000 \\
\hline
\end{tabular}

It is worth mentioning that in the group PI, there were no occurrences of the processing errors commonly observed in the written and oral production of Brazilian learners, namely, sentences using the L1 processing:

Subject + verb to be + noun

Subject + have + noun.

On the other hand, there were 11 occurrences of this type of error in the groups TI, both extensive and intensive classes.

\section{Discussion}

Our research questions were the following: will learners who receive the pedagogical intervention PI show significantly higher gains in the posttest when compared to learners who received traditional instruction? Will learners in intensive courses of both types of interventions have significantly higher gains than those in regular programs?

The hypothesis of the study seems to have been corroborated, considering that the differences between the groups of interventions in the posttest revealed a better performance for the group PI. This strongly suggests that the variable type of instruction was responsible for this difference in the results obtained by the participants. Processing Instruction seemed to be significantly more effective when combined with a program of daily lessons.

PI model assumes that it is as an essential part of the intervention the task of bringing to learners' attention potential problems of processing involved in the acquisition of certain grammatical forms. On the other hand, the traditional approach hardly ever predicates on what learners do during input processing, partly because very little attention is given to the influence that L1 has on the learners' developing system. Mostly, teachers are not allowed to make any sort of comparisons with the native language that may be needed in order to understand what should be done and what should not. This difference between PI and TI in addressing the input processing plays a very important role in the teaching planning as a whole. Mainly because when adopting the PI intervention, teachers will be able to attempt to enhance learners' attention to potential errors while working with explicit teaching. Secondly, teachers are able to work with implicit learning mechanisms while using structured input activities. These exercises function particularly well when complex grammatical properties are the very target of the lesson.

Although we counted on the most unrestricted cooperation of the English school where the research was conducted, it should be noted that the distribution of students by the number of teachers was far from ideal. We also had to manage the leave sick of one of the teachers, which may have motivated some students to change their schedule and virtually empty a classroom. As a result, we had a class with only two students, since the others have missed one or two interventions. Furthermore, although the experimental questions were repeated in the pre and post-test, the latter was rather different from the former. Considering that the targeted grammatical form and the warm-up were based on the textbook of the previous level, teachers felt afraid of being observed in some sort of auditing process to assess their teaching of the level 1 of their course. Therefore, it was necessary to include a large number 
of distractors in the pre-test. Another reason for this difference between the tests was the fact that we wanted to prevent students from remembering the questions and their replies to them in the pre-test. Apart from this factor, it is worth mentioning that the number of subjects in the sample was relatively small. Unfortunately, from the 77 students initially contacted, only 51 remained until the end of the treatments and post-tests due to absenteeism. The sample, therefore, could have been more representative, especially for intensive PI Group, which had only eight students whereas there were 13 students in the intensive IT Group.

Despite these and other limitations, we believe that this study has contributed to a better understanding of the phenomenon of acquiring a second language in the specific context of a monolingual country like Brazil. We sought to understand the importance of information processing as a relevant variable in the learning of this particular target form. The teaching of English as a typologically hybrid language, i.e. showing both Anglo-Saxon and Latin languages properties, presents a major difficulty in syntactic aspects for Brazilian learners as the lexical similarities do not necessarily entail resemblance in word order. It is expected that the small step taken by this research will encourage further studies in Instructed Second Language Acquisition in Brazil. Suffice it to say, at the beginning of this study, there was still no research on Processing Instruction with Portuguese as L1 and English as L2.

This research was conducted under the supervision of Prof. Dr. José Fernando Bitencourt Lomônaco of the Institute of Psychology of Universidade de São Paulo, São Paulo, Brazil.

\section{References}

[1] Ellis, R. Second Language Acquisition, 2nd edition, Oxford University Press, Oxford, 2012.

[2] Gass, S. and Selinker, L. Second Language Acquisition: An Introductory Course, 2nd ed., Johns Benjamin, Amsterdam, 2001.

[3] R. Schwartz, "Psychological Mechanisms Underlying Second Language Fluency", Studies in Second Language Acquisition, vol. 14, Cambridge University Press, Cambridge, 1983, pp. 357-385.

[4] C.A. Seger, "Implicit Learning", Psychological Bulletin, vol. 115, $\mathrm{N}^{\mathrm{o}} 2$, Wiley Online Library, Hoboken, NJ, 1994, pp. 163-196.

[5] B. VanPatten, "Processing instruction: an update", Language Learning, vol. 52, Wiley Online Library, Hoboken, NJ, 2002, pp. 755-804.

[6] B. VanPatten, "The two faces of SLA: Mental Representation and Skill”, International Journal of English
Studies, vol. 10, Servicio de Publicaciones de la Universidade de Murcia, Murcia, 2010, pp. 1-18.

[7] VanPatten B. and Cadierno. "Input Processing and Second Language Acquisition: A Role for Instruction", The Modern Language Journal, vol. 77, issue: 1: Wiley Online Library, Hoboken, NJ, 1993, pp. 45-57.

[8] L. White, Second Language Acquisition and Universal Grammar, 1st ed., Cambridge University Press: Cambridge, 2003.

[9] Witter, G.P. and Lomonaco, J.F.B. Psicologia da Aprendizagem, $3^{\text {a }}$ reimpressão, São Paulo: E.P.U, 2007.

[10] S. Krashen, "We Acquire vocabulary and Spelling by Reading: Additional Evidence for the Input Hypothesis", The Modern Language Journal, vol. 73, Wiley Online Library, Hoboken, NJ, 1989, pp. 440-64. 


\section{Appendix A}

Sample Activities Used In Processing Instruction

Structured Input activities.

Listen to your teacher. He/she will say the beginning of the sentence and you choose the best alternative.

1) is tired
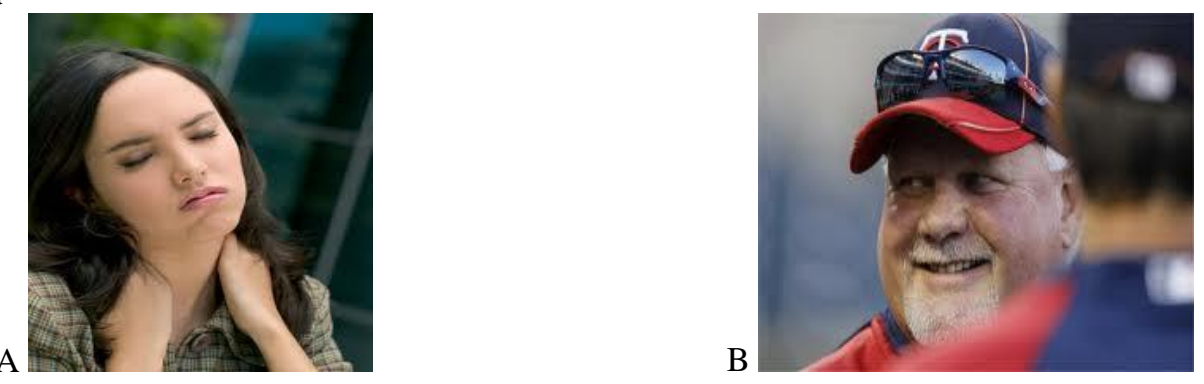

2) is sure
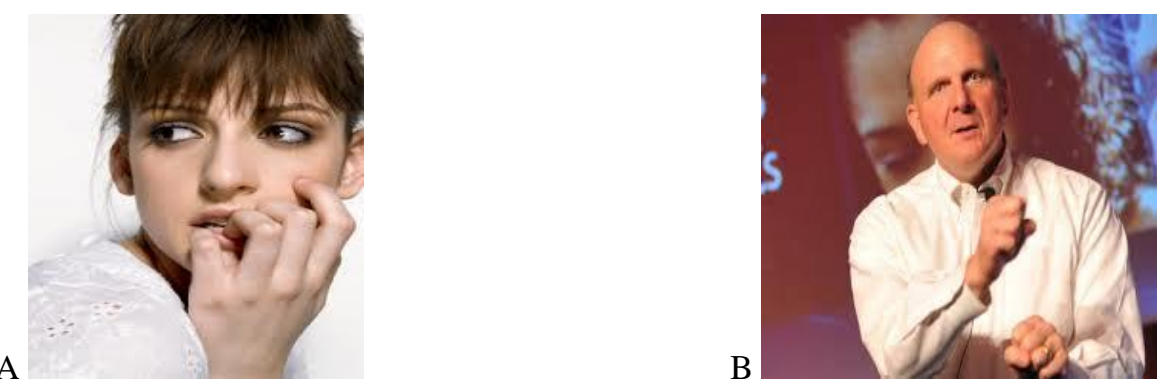

3) is hungry
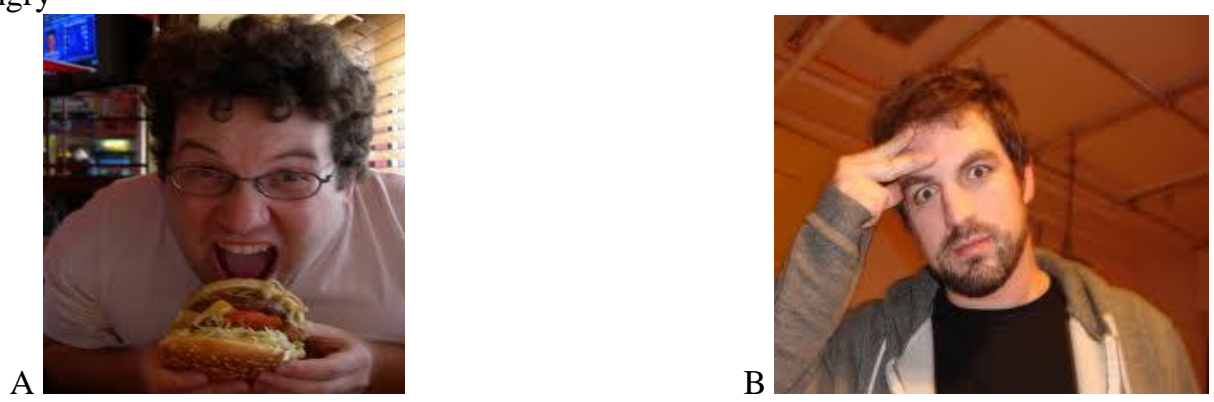


\section{Appendix B}

Sample Activities Used In Processing Instruction

Structured Input activities.

Listen to your teacher. He/she will say the beginning of the sentence and you choose the best alternative.

1) This is the right direction. I ...
a) .... have sure.
b) .... have certainty.
c) $\ldots$ am sure.

2) I don't watch horror movies. I...
a) .... have afraid
b) .... am afraid.
c) .... am fear.

3) Turn on the air conditioning. I...
a) .... am hot.
b) .... am with hot.
c) ... have hot.

4) Dou you have water in your refrigerator?
a) .... have thirst.
b) .... am thirsty.
c) .... am with thirst.

5) It's 1pm, Let's go to that fast food. I ...
a) $\ldots$ am hungry.
b) .... have hungry.
c) .... am with hunger. 


\section{Appendix C}

Sample Activities Used In Processing Instruction

Structured Input activities.

1) Speaking English every day is good to practice new vocabulary. I know it. I...
a) ... am afraid to make mistakes, so I never speak.
b) ... am not afraid do make mistakes. I always speak English.

2) A vocabulary notepad is excellent to organize the new words. I ...
a) ... am sure it is good.
b) ... am not sure it is good.

3) About English classes in the morning. I ...
a) ... am not sleepy at this time, I like it.
b) ... am sleepy at this time. I don't like it.

4) Brazil is not a bilingual country. We only speak Portuguese. I...
a) ... am lucky to live in Brazil.
b) ... am not lucky to live in Brazil.

5) About English classes at lunch time. I...
a) ... am hungry at this time. I don't like it.
b) ... am not hungry at this time. I like it.

6) About the temperature in your classroom now. I...
a) ... am cold. I need a sweater or a jacket.
b) ... am hot. The temperature is not nice. 


\section{Appendix D}

Sample of Explicit Information of Processing Instruction

Grammatical explanation - guidelines for teachers.

1) Show these examples and ask them if they find a pattern as to the position of the adjectives: Fast food, White House, American Airlines, New houses, American Idol.

After that, explain the following:

a) Adjectives go before a noun. NOT “it's a house new”.

b) Adjectives don't change before a plural noun. NOT “They're prettys flowers”.

\section{Explain in this part of the instruction in Portuguese.}

Brazilians usually process this type of psychological states by using nouns and not adjectives as it is the case in English.

- I'm hungry = estou com fome

- I'm thirsty = estou com sede

- I'm sure = tenho certeza

- I'm cold = estou com frio

- I'm hot = estou com calor

- I'm sorry = eu sinto muito.

- I'm afraid = tenho medo

- I'm lucky = estou com sorte.

- I'm careful = tenho cuidado com algo. 